\title{
EDUCAÇÃO EM CIÊNCIAS NA PERSPECTIVA DA TEORIA DA SOCIEDADE DO CONHECIMENTO DE NICO STEHR
}

\author{
MARINA DE FREITAS ${ }^{+}$ \\ https://orcid.org/0000-0001-8618-1292 \\ LEONARDO ALBUQUEROUE HEIDEMANN" ** \\ https://orcid.org/0000-0001-5143-6275 \\ IVES SOLANO ARAUJO" *** \\ https://orcid.org/0000-0002-3729-0895
}

RESUMO: A Abordagem CTS tem se preocupado com as implicações dos estudos sobre as relações entre Ciência, Tecnologia e Sociedade (CTS) na área de ensino de ciências. Nessa perspectiva, o ensino deve se basear numa visão de ciência como processo social, assumindo que o desenvolvimento científico e tecnológico não é neutro. Com o objetivo de ampliar os horizontes da área quanto às discussões contemporâneas sobre a função social do conhecimento, especialmente o conhecimento científicotecnológico, o presente artigo tem como objetivo apresentar a Teoria da Sociedade do Conhecimento, na acepção do sociólogo Nico Stehr, como um referencial teórico possível para a análise sociológica do papel do conhecimento nas sociedades modernas e apresentar as potencialidades dessa teoria para o ensino de ciências.

Palavras-chave: CTS. Sociedade do Conhecimento. Ensino de ciências.

\section{EDUCACIÓN EN CIENCIAS EN LA PERSPECTIVA DE LA TEORÍA DE LA SOCIEDAD DEL CONOCIMIENTO DE NICO STEHR}

RESUMEN: El enfoque CTS se preocupa por las implicaciones de los estudios acerca de las relaciones entre Ciencia, Tecnología y Sociedad (CTS) en el área de la enseñanza de ciencias. En esa perspectiva, la enseñanza debe basarse en una visión de ciencias como proceso social, considerando que el desarrollo científico y tecnológico no es neutro. Con el objetivo de ampliar los horizontes del área con relación a las discusiones

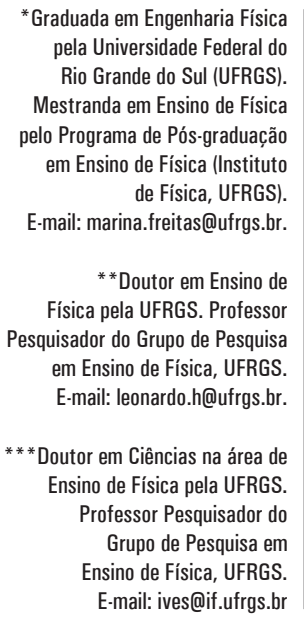

*Graduada em Engenharia Física pela Universidade Federal do Rio Grande do Sul (UFRGS). Mestranda em Ensino de Física pelo Programa de Pós-graduação em Ensino de Física (Instituto de Física, UFRGS).

E-mail: marina.freitas@ufrgs.br.

* *Doutor em Ensino de Física pela UFRGS. Professor Pesquisador do Grupo de Pesquisa em Ensino de Física, UFRGS. E-mail: leonardo.h@ufrgs.br.

***Doutor em Ciências na área de Ensino de Física pela UFRGS. Professor Pesquisador do Grupo de Pesquisa em Ensino de Física, UFRGS. E-mail: ives@if.ufrgs.br

I Universidade Federal do Rio Grande do Sul, Programa de Pós-graduação em Ensino de Física, Porto Alegre, RS - Brasil.

II Universidade Federal do Rio Grande do Sul, Grupo de Pesquisa em Ensino de Física, Porto Alegre, RS - Brasil. 
contemporáneas acerca de la función social del conocimiento, especialmente el conocimiento científico-tecnológico, este artículo tiene el objetivo de presentar la Teoría de la Sociedad del Conocimiento, acepción del sociólogo Nico Stehr, como un marco teórico posible para el análisis sociológico del rol del conocimiento en las sociedades modernas y presentar las potencialidades de esa teoría para la enseñanza de ciencias.

Palabras clave: CTS. Sociedad del Conocimiento. Enseñanza de ciencias.

\section{SCIENCE EDUCATION IN THE PERSPECTIVE OF THE KNOWLEDGE SOCIETY THEORY OF NICO STEHR}

ABSTRACT: The STS Approach has been focused on the studies implications about the relations between Science, Technology, and Society (STS) on science teaching. From this perspective, education should be based on a view of science as a social process, assuming that scientific and technological development is not neutral. The purpose of this article is to present the Knowledge Society Theory, in the sense of sociologist Nico Stehr, as a possible theoretical framework for the sociological analysis of the role of knowledge in modern societies, and present the potentialities of his theory for science education.

Keywords: STS. Science Education. Knowledge Society. 


\section{INTRODUÇÃO}

Desde que Thomas Kuhn publicou seu livro "A estrutura das revolucões cientificas" e de que Rachel Carson publicou a "Primavera Silenciosa", ambos em 1962, os estudos sobre as relações entre Ciência, Tecnologia e Sociedade (CTS) têm abordado o desenvolvimento científico e tecnológico como um fenômeno social (AULER, 2011; BATISTA DE FREITAS, 2019; NÚÑEZ JOVER, 2000), seguindo diferentes vertentes quanto à abordagem (campo investigativo, de políticas públicas ou da educação) e à origem (Latino-Americana, Europeia e Norte-Americana) (STRIEDER, 2012). Apesar da diversidade de perspectivas, autores da área convergem sobre a necessidade de que o ensino se fundamente num entendimento de ciência como processo social, assumindo que o desenvolvimento científico e tecnológico é influenciado pelos valores e morais dos seus contextos sociais, ou seja, não é neutro (AULER, 2011; BATISTA DE FREITAS, 2019; DAGNINO, 2006; NÚÑEZ JOVER, 2000; STRIEDER, 2012). No campo da educação, a pesquisa CTS tem como objetivo geral desenvolver um "ensino de ciências mais crítico e contextualizado, que contribua para promover a participação da sociedade em questões relacionadas ao desenvolvimento científico - tecnológico” (STRIEDER, 2012, p. 27).

Segundo Auler e Delizoicov (2001), paira no senso comum o mito da neutralidade científica ou, ainda, da inevitabilidade do progresso e da acriticidade em relação à ciência e tecnologia (AULER, 2011; AULER; DELIZOICOV, 2001). Dele se originam as crenças de que: a ciência é redentora, capaz de resolver todos os problemas da sociedade; o desenvolvimento tecnológico é o motor das mudanças sociais, sempre positivas; a ciência segue um caminho linear que seguramente levará a um aumento do bem-estar social. Esses mitos, chamados assim pelos autores porque costumam estar "blindados" de críticas, conduzem os indivíduos a um "sonambulismo tecnológico" que pode encaminhar a sociedade à tecnocracia, ${ }^{1}$ fragilizando os aspectos democráticos da sociedade. Assim, as abordagens CTS defendem uma educação científica que não reproduza esses mitos, mas que os problematize (AULER; DELIZOICOV, 2001).

O CTS brasileiro - fortemente vinculado aos escritos de Paulo Freire (AULER, 2011; AULER; DELIZOICOV, 2001; SANTOS; MORTIMER, 2000) - propõe uma educação científica crítica que não se resuma à discussão de ciência e tecnologia, mas que englobe também aspectos políticos, ambientais e sociais (SANTOS; MORTIMER, 2000); uma educação científica que forme sujeitos autônomos e problematizadores, críticos em relação à concepção de ciência redentora e que seja composta de estratégias educacionais que se adaptem à situação socioeconômica e cultural dos professores, estudantes e sistemas educacionais (AULER, 2011; AULER; DELIZOICOV, 2001; STRIEDER, 2012). Ainda assim, Strieder constata que há uma escassez de discussões atualizadas sobre a função social da ciência (STRIEDER, 2012). Apesar de indicar avanços nas discussões acerca das relações entre ciência e tecnologia com o espaço social, a autora reforça que essas discussões seguem pouco incorporadas ao ensino de ciências, possivelmente uma consequência da falta de referencial teórico sobre o assunto na educação (STRIEDER; KAWAMURA, 2017).

Dentre os caminhos para ampliar e atualizar o debate sobre a função social da ciência, pode-se buscar articular à área da educação teorias que buscam descrever o papel do conhecimento científico nas sociedades modernas. Desde 
o início do século XX, tem se desenvolvido, principalmente nas ciências sociais, teorias que descrevem as sociedades modernas como sociedades do conhecimento (ADOLF; STEHR, 2017; STEHR, 2018). O conceito ganha destaque a partir dos trabalhos de Peter Drucker - em The Age of Discontinuity, publicado em 1968 - e das discussões de Daniel Bell sobre sociedade pós-industrial, iniciadas também no início da segunda metade do século XX, e se diferenciam pelo importante papel econômico atribuído ao conhecimento (ADOLF; STEHR, 2017). O sociólogo alemão Nico Stehr propôs sua acepção de uma Teoria da Sociedade do Conhecimento (TSC), onde analisa o conhecimento de uma perspectiva econômica e social e, diferentemente das teorias anteriores, não apresenta o conhecimento como uma "caixa-preta", e sim como uma entidade peculiar com propriedades únicas que esculpem as sociedades modernas (ADOLF; STEHR, 2017). Sua teoria enfoca aspectos diferentes das abordagens mais conhecidas de Sociedades do Conhecimento, principalmente as apresentadas pela UNESCO, pelo Banco Mundial e pelas Nações Unidas (RUSER, 2018), diferindo em parte, como será discutido posteriormente, das abordagens mais frequentes, como as apresentadas por Duarte (2013, p. 5-16) e Aikenhead et al. (2011).

Ao descrever o conhecimento como uma capacidade de ação e classificálo como principal recurso dos processos produtivos econômicos contemporâneos (ADOLF; STEHR, 2017; STEHR, 2018), Stehr busca descrever as novas relações entre a sociedade civil e as grandes instituições, as relações entre poder, autoridade e conhecimento, sua relação com as desigualdades sociais e em que medida o conhecimento pode ser tratado como uma propriedade ou como uma mercadoria. A fim de ampliar as investigações sobre o papel social do conhecimento científico-tecnológico no ensino de ciências, o presente artigo tem como objetivo apresentar a TSC de Nico Stehr como um referencial teórico possível para a análise sociológica do papel do conhecimento nas sociedades modernas, e discutir as potencialidades dessa teoria para o ensino de ciências.

A teoria se caracteriza por ser estruturada e abranger diversos aspectos da sociedade, descrevendo detalhadamente as características e funções do conhecimento em um contexto geral. Se por um lado essas propriedades contribuem para que a teoria seja aplicada em diferentes realidades, também requerem que a situação analisada seja cuidadosamente considerada, de forma que não se recaia em conclusões ingênuas. Por isso, é crucial que se considere as discussões brasileiras contemporâneas sobre as consequências da Era do Conhecimento (ALVES; BAUMGARTEN, 2019; BAUMGARTEN, 2002; LASTRES et al., 2002; MACIEL; ALBAGLI, 2011) para que conclusões e ações mais precisas e coerentes sejam obtidas.

\section{SOCIEDADES DO CONHECIMENTO}

A TSC analisa as sociedades em que o conhecimento é o elemento fundamental do crescimento e desenvolvimento econômicos. Segundo essa teoria, as fontes de crescimento econômico e das atividades de valor agregado das sociedades do conhecimento advêm do conhecimento, pois ele é o principal recurso dos processos produtivos econômicos (STEHR, 2018). Conhecimento, nessa abordagem, é capacidade de ação (ADOLF; STEHR, 2017, p. 1), independente de sua origem e objetivo. Primeiro, serão apresentadas as características gerais das sociedades 
do conhecimento; em seguida, as características peculiares do conhecimento, suas consequências e discussões decorrentes delas.

Nas sociedades do conhecimento as grandes instituições sociais - o estado, a economia, a ciência etc. - perderam legitimidade, autoridade e o poder de completo controle da sociedade. Permanecem, porém, tendo poder, principalmente quando são polos de concentração das capacidades de ação. Ao mesmo tempo, os indivíduos e pequenos grupos se tornaram capazes, dentro de algumas regras, de assegurar seus interesses através da oposição ou resistência a essas grandes instituições sociais. Com mais direitos políticos, esses grupos conquistaram o direito de dizer não: exercem seus direitos também na forma de não-participação e negação de atividades políticas, bem como com a diminuição do senso de responsabilidade individual. Somando-se aos imprevistos provocados pelo alto fluxo de conhecimento, esses fatores têm como consequência uma crise no domínio, planejamento e gestão de problemas comuns, o que torna a sociedade mais frágil e vulnerável. A fragilidade se agrava com a dependência dessas grandes instituições de tecnologias como a geração de energia, a internet e sistemas computacionais complexos, que as deixam vulneráveis a imprevistos, como a catástrofes ambientais (STEHR, 2018).

$\mathrm{O}$ acesso ao conhecimento depende e molda as oportunidades de vida, o estilo de vida e a influência social do indivíduo, ou seja, a participação no ato de conhecer está sujeita à estratificação (ADOLF; STEHR, 2017). Em formas anteriores de sociedade, apesar de o conhecimento exercer poder e influência sobre os indivíduos, de ser a base para a ação humana, esses não dependiam sobremaneira do acesso a ele para sua sobrevivência, para suas relações sociais, nem para obtenção de renda ou alimento; suas vidas dependiam mais significativamente do acesso aos meios de produção, da capacidade de ser produtivo, ou da possibilidade de trabalho agrário, por exemplo. Nas sociedades do conhecimento, essa relação de dependência com o conhecimento muda, pois ele passa a ser fundamental para a vida social (ADOLF; STEHR, 2017).

A principal transformação que a estrutura econômica sofre ao passar para uma sociedade do conhecimento - partindo de uma sociedade industrial - é o deslocamento do recurso de entrada nos processos produtivos. A produção industrial, a propriedade e o "labor" deixam de ser o motor principal da economia das sociedades modernas avançadas e abrem espaço para o protagonismo do conhecimento. A influência de elementos como o tempo de trabalho e o capital físico perdem importância como fatores dos processos produtivos diante da relevância do conhecimento nesses processos. Ademais, ainda que os recursos materiais (recursos naturais, minerais, água, carvão, petróleo etc.) continuem sendo importantes nessas sociedades, os recursos simbólicos baseados no conhecimento se tornam ainda mais relevantes, tornando-se os principais recursos da estrutura econômica das sociedades (STEHR, 2018).

Apesar de terem se originado das sociedades industriais, as sociedades do conhecimento não são fruto de um planejamento, nem de uma revolução, e sim resultado de transformações graduais (ADOLF; STEHR, 2017). As diferentes sociedades do conhecimento não possuem um padrão de costumes e culturas unificado: é, na verdade, a possibilidade de serem diferentes que as definem. Amplificados pelas novas tecnologias da comunicação, grupos e culturas se mesclam, se recriam ou se isolam; não mais obedecem a designações comportamentais de uma mesma instituição (STEHR, 2018). 


\section{CONHECIMENTO: CARACTERÍSTICAS E PROPRIEDADES}

A acepção de Stehr se destaca pela sua abordagem ao conhecimento. Como ele mesmo aponta, de uma ótica sociológica, sua teoria não trata o conhecimento como uma "caixa-preta". Investiga não só a atuação do conhecimento na economia e sociedade, como também busca caracterizar o conhecimento em $\mathrm{si}^{2}$ como capacidade de ação (ADOLF; STEHR, 2017). O termo capacidade é usado para descrever as possibilidades que o conhecimento oferta; expor a possibilidade de múltiplas implicações e consequências; e sinalizar que o conhecimento pode ser usado para fins “irracionais". Essa definição implica que a aplicação do conhecimento não é fixa, nem livre de incertezas, e que nem todo o conhecimento tem um fim prático ou útil, nem que é baseado em fatos, nem que reflete uma realidade objetiva - seja ele científico, tecnológico, ou de outra forma. Tampouco aponta para qualquer característica neutra ou intrinsecamente boa do conhecimento, pois depende intimamente do contexto social, econômico e das condições intelectuais do indivíduo, grupo ou instituição que o detém (ADOLF; STEHR, 2017; STEHR, 2018).

Conhecimento é um potencial de ação, pois é necessário para a afirmação do poder: pode-se ter autoridade, poder e acesso aos recursos necessários, mas sem o conhecimento pode-se não ter a capacidade de agir necessária. O conhecimento então constitui uma base para o poder. ${ }^{3}$ Em especial o conhecimento adicional (também chamado incremental), pois representa avanço em relação aos outros (concorrentes, inimigos etc.). Assim, não basta possuí-lo; é preciso continuamente produzi-lo. Em contrapartida, o conhecimento flui do poder na medida em que aqueles com poder o possuem, não por terem acesso a informações privilegiadas sobre a verdade objetiva, mas porque "aqueles que têm a capacidade de reivindicar o que é verdade (conhecimento) têm uma reivindicação de poder" (ADOLF; STEHR, 2017, p. 63). Portanto, conhecimento e poder são entidades diferentes, mas que, entrelaçadas, criam uma à outra. ${ }^{4}$

Por ser uma capacidade de ação, o conhecimento nos permite: colocar algo em movimento ou impedi-lo; criar e destruir; sustentar, manter e perpetuar; e agir sobre condições externas e internas, individuais ou coletivas (ibid.). Mas nem tudo que é convencionalmente classificado como conhecimento é, segundo essa perspectiva, uma capacidade de ação.

Stehr classifica como informação todo conteúdo que possa ser quantificado - expresso na forma de texto, tabela, mapas, calendários, gráficos etc. Por depender do uso de ferramentas e habilidades intelectuais específicas para sua interpretação, a informação não é, por si só, uma capacidade de ação (ibid.). Por exemplo, dados estatísticos sociais são informações que refletem a sociedade; suas interpretações são conhecimentos construídos a partir deles e são capacidades de agir sobre a sociedade. A informação, sem a participação de um ente que a interprete e decifre, não é uma capacidade de ação.

Em relação ao conhecimento científico e tecnológico, Stehr rejeita a ideia de que eles possuam alguma característica fundamental de eficiência de ação, de que são incontestáveis, de que não estão sujeitos a interpretação e de que podem ser transmitidos sem impedimento. Se consideradas as necessidades específicas e restritas (contextuais) necessárias para a reprodução do conhecimento científico e 
tecnológico, é direto o entendimento de que esse conhecimento não é universal e de que não é acessível a todos (ADOLF; STEHR, 2017; STEHR, 2018). A abordagem sociológica do conhecimento escolhida por Stehr descreve o conhecimento científico como um produto coletivo histórica e socialmente baseado, que não é incontestável e tampouco é a única forma de conhecimento humano (ADOLF; STEHR, 2017).

Stehr ressalta que geralmente se assume que o custo de produção do conhecimento tecnológico é alto, enquanto os custos de sua disseminação são reduzidos aos custos nominais ${ }^{5}$ da obtenção de esquemáticos e especificações técnicas. Contudo, em alguns casos, apenas informações superficiais sobre o conhecimento tecnológico estão codificadas e objetificadas em meios não pessoais de comunicação (como tutoriais, desenhos e esquemáticos) e parte dele se encontra atrelado ao próprio fazer técnico (intrinsecamente associada aos especialistas que as (re)produzem). Ao se resumir o conhecimento tecnológico a esquemáticos técnicos (informações), ignora-se que sua reprodução exige também as habilidades cognitivas necessárias para gerá-lo - geralmente complexas, sofisticadas, raras e caras (ibid.). Como resultado, o autor destaca que a disseminação do conhecimento tecnológico pode ser tão, ou mais, cara do que sua produção, suscitando o questionamento se produção e disseminação - no sentido de reprodução - de conhecimentos podem realmente ser separadas (ADOLF; STEHR, 2017).

A exemplo, o esquemático de um circuito de uma placa eletrônica não contém todas as informações necessárias para se compreender a vastidão de conhecimentos que o envolvem. Há um conhecimento subliminar nesses desenhos técnicos, tais como teorias associadas ao eletromagnetismo e a ciência dos materiais, bem como saberes práticos sobre eletricidade e eletrônica. Além disso, o esquemático não codifica os conhecimentos necessários para a produção da placa - tais como a conservação dos componentes eletrônicos, ou a escolha da técnica e equipamento de fabricação -, nem para sua calibração e validação. Todos esses elementos, da idealização teórica à produção do produto, são conhecimentos tecnológicos; eles abrangem muitos mais componentes do que aqueles codificados nos esquemáticos e especificações técnicas, pois incluem também saberes que estão intimamente associados às práticas de produção de conhecimento e que não são facilmente materializados. Portanto, a disseminação do conhecimento tecnológico não pode ser facilmente separada das práticas que envolvem sua própria produção.

Por ser intangível e não-rival, ${ }^{6}$ o conhecimento não está sujeito à escassez. Porém, ele possui dois aspectos que podem o transformar em escasso. Primeiro, o acesso ao conhecimento incremental é restrito e mais difícil de ser obtido do que as demais partes do conhecimento. O conhecimento incremental é uma unidade de conhecimento que avança além do conhecimento geral, possuindo grande potencial de influência, pois representa uma vantagem - econômica, política etc. - daqueles que o têm. Quanto maior o tempo de decaimento desse incremento, ou seja, quanto maior o tempo para que seja integrado ao corpo geral de conhecimentos, mais poder seu possuidor dispõe. O conhecimento incremental, ou adicional, promove uma vantagem cumulativa de aprendizado que implica numa competição desequilibrada, que é elemento constitutivo da economia em uma sociedade do conhecimento (STEHR, 2018).

O segundo aspecto que torna o conhecimento escasso é a restrição à habilidade cognitiva de gerar e interpretar o conhecimento (ibid.). Por exemplo, integrar e derivar 
em cálculos matemáticos, soldar componentes eletrônicos, analisar dados estatísticos, compreender desenhos industriais, esquemáticos técnicos etc., são habilidades que podem ser necessárias, por exemplo, para construir e validar um equipamento científico, ou para produzir um componente eletrônico. Porém, quando restritas, impossibilitam que a informação disponível vire uma capacidade de ação, um conhecimento.

O acesso, por exemplo, a esquemáticos técnicos de um circuito eletrônico, ou seja, à informação objetificada sobre um circuito, não é suficiente para sua reprodução. Para além de recursos materiais, ${ }^{7}$ é preciso que o indivíduo tenha habilidades cognitivas, para interpretar o esquemático e técnicas para a construção de um circuito. Assim, conhecimentos que necessitam de habilidades pouco difundidas se transformam em conhecimentos escassos, independentemente da disponibilidade do conhecimento objetificado associado a eles. Um caso análogo envolve a obtenção de um equipamento científico. Ao ser vendido, não transfere consigo, usualmente, o conhecimento de calibração e validação do próprio. A não transferência dessas habilidades cognitivas dá aos seus possuidores vantagens na produção de conhecimento adicional e gera dependência dos que não as possuem (STEHR, 2018).

\section{VALOR ECONÔMICO DO CONHECIMENTO}

Na sociedade do conhecimento, o conhecimento é a força produtiva de maior influência no capital econômico. Como modo de produção, substitui as formas típicas de uma sociedade industrial (propriedade e capital). Logo, é uma fonte de valor adicional, crescimento econômico e produtividade (ibid.). Suas duas expressões de maior significado econômico são: a emergência do conhecimento científico como força produtiva imediata; e a disputa por classificar o conhecimento como propriedades (ou mercadorias) (ADOLF; STEHR, 2017).

O conhecimento científico e tecnológico se transforma em força produtiva imediata, e consequentemente fonte de crescimento econômico, quando produz informações (dados, técnicas, programas, teorias) que representam capacidades de ação que se transformam em componentes constitutivos da sociedade. É também um tipo de conhecimento relevante para produção, sem a necessidade de intermédio de força de trabalho braçal (ibid.). O conhecimento científico e tecnológico produz capacidades incrementais para a ação social e econômica que aumentam a habilidade do "saber fazer". As capacidades adicionais podem ser capitalizadas e serem força de produção ou resultado de um processo (ibid.).

O conhecimento científico e técnico é delimitado pelo volume de recursos necessários e pela complexidade associada à implementação de uma capacidade de ação, a dificuldade de "pôr um conhecimento em prática". Por recursos se pode entender desde matéria-prima até infraestrutura e recursos humanos indispensáveis para essa prática. Associada à implementação de um conhecimento científico está uma complexa rede de habilidades, informações e conhecimentos encadeados que se fazem cruciais para sua execução. Se atualmente a produção de conhecimento não está mais limitada a um determinado tempo e espaço, sua interpretação e uso (prático) passam a depender fortemente do tempo, localização e circunstâncias. É o trabalho de interpretação executado por especialistas que complementa as limitações práticas do conhecimento científico e o contextualiza (ADOLF; STEHR, 2017; STEHR, 2018). 
Esses limites são parte inerente do processo de produção e reprodução do conhecimento científico e técnico; estabelecem a importância, nas sociedades avançadas, do papel desempenhado por especialistas em ocupações baseadas no conhecimento, como engenheiros e cientistas, e limitam o poder social do conhecimento científico. Assim, como responsáveis por extrair do conhecimento as ações práticas desejadas, os engenheiros e cientistas são a força de trabalho da sociedade moderna. O seu prestígio social e a autoridade serão maiores quanto mais próximos do conhecimento adicional estiverem (ADOLF; STEHR, 2017; STEHR, 2018).

A importância econômica do conhecimento só faz acirrar o debate político sobre a propriedade intelectual. Para alguns autores (EVENSON; PUTNAM, 1987, apud ADOLF; STEHR, 2017), sem a intervenção do Estado, o conhecimento é naturalmente um bem comum, seja por questões normativas (como o ideal da ciência como um conhecimento coletivo), seja por seus atributos não-materiais e não-rivais. Não há, porém, nenhuma característica essencial do conhecimento que o impeça de ser uma mercadoria. A exemplo, o conhecimento geral disponível não é nem completamente exclusivo, nem completamente sem rival, e seu uso está, em geral, restrito, seja por mecanismos legais, seja por estar incorporado em instrumentos e artefatos (ADOLF; STEHR, 2017).

$\mathrm{Na}$ tentativa de classificar o conhecimento como uma mercadoria, seu caráter não-rival impõe uma enorme dificuldade em determinar o valor econômico (monetário) de uma unidade de conhecimento e de estabelecer direitos de propriedade sobre ele. As tentativas de monetizar o conhecimento levam, em sua maioria, a monetização da informação, ou da sua monetização apenas como entrada ou saída na cadeia produtiva (ADOLF; STEHR, 2017). Essa classificação se baseia no protagonismo de corporações no direcionamento das pesquisas científicas, mas também é motivo de crítica quando do patenteamento de conhecimentos sensíveis (como os genes). Os mecanismos legais de propriedade intelectual (patente, direitos autorais e marca registrada) buscam privatizar o uso e acesso ao conhecimento, mas não há garantias de que conseguem ser aplicados (ADOLF; STEHR, 2017).

A parte do conhecimento que pode ser entendida como uma mercadoria, e assim mais fácil de controlar, é o conhecimento adicional. A facilidade de exercer controle e privatizar esse conhecimento o torna estratégico (ADOLF; STEHR, 2017), pois ele acrescenta valor econômico a uma mercadoria por ser uma inovação que o consumidor não tinha acesso anteriormente. Assim, por interesse das indústrias e corporações que financiam pesquisas, o conhecimento incremental está sujeito a ser um conhecimento rival e excludente. Curiosamente, devido à alta taxa de produção de conhecimento, os conhecimentos adicionais rapidamente aparecem e desaparecem, sendo superados por novos ou rapidamente difundidos e apropriados (ibid.).

O valor investido para a produção do conhecimento adicional está inserido no capital humano e físico, mas também em toda infraestrutura indiretamente usada nessa produção, o que dificulta ainda mais a sua monetização. Associado a ele está uma rede de infraestruturas (institutos de educação, bibliotecas, mídia, editoras etc.) que fogem do controle direto das corporações, mas que devem ser sustentadas (ibid.).

Apesar de haver várias estratégias para encarar o conhecimento como propriedade, não há uma forma concreta, fixa e inequívoca de defini-lo como uma propriedade econômica convencional (ibid.). Para Stehr, o conhecimento é 
muito valioso e especial para ser medido unicamente num sentido monetário. A sabedoria, insights e experiência não estão à venda no mercado, e nem por isso deixam de possuir valor; sua restrição e exclusividade são quase impossíveis devido a sua característica inerente de intangibilidade (não-materialidade) e a crescente facilidade de armazenar e compartilhar informação (ibid.).

\section{DESIGUALDADES SOCIAIS NAS SOCIEDADES DO CONHECIMENTO}

Em sua análise, Stehrindica que, na medida em que as sociedades industriais se transformaram em sociedades do conhecimento, também as teorias sobre desigualdade social deveriam ser reformuladas para abarcar essas transformações. As teorias baseadas nas sociedades industriais explicam a desigualdade social como essencialmente resultado da relação do indivíduo com o trabalho (ou com o seu capital de ganhos), da mesma forma que os estratos e classes sociais são determinados por essa relação (STEHR, 2000). Já Stehr destaca que análises recentes das sociedades mostram que, devido ao acúmulo de riqueza pessoal e familiar, e do estabelecimento de um pacote de direitos de cidadania e bem-estar social garantidos, houve uma diminuição da subordinação direta do indivíduo à sua posição ocupacional no mercado de trabalho. Stehr ressalta ainda que, para além da ocupação do indivíduo, há outros atributos que levam à desigualdade, tais como: o acesso à seguridade social, a serviços sociais, aos recursos de lazer, e a desigualdade de tratamento devido a características imputadas (STEHR, 2000).

$\mathrm{O}$ autor indica que um processo de descentramento está ocorrendo nas sociedades modernas: elas perderam os centros de autoridade fixos e os padrões de conduta exemplares e rigidamente limitantes. O que se vê é a multiplicação de partidos políticos, padrões familiares, estruturas de gênero, disciplinas científicas, grupos étnicos, comunidades, cidades, estratos sociais etc. Esse processo de descentramento produz estruturas maleáveis que podem reconstruir as regras que governam os padrões estruturais (ibid.). A flexibilidade e maleabilidade das novas realidades têm como consequência uma inversão na relação entre bemestar material e conhecimento: o segundo passa a comandar o primeiro. Como resultado, a desigualdade social nas sociedades do conhecimento é menos visível e óbvia do que nas sociedades industriais (ibid.).

É neste cenário maleável que a capacidade de ação originada do conhecimento ganha um papel de protagonismo na estratificação do indivíduo. Aqueles dotados de conhecimento são capazes de mobilizar recursos que os protegem e isolam dos impactos imediatos do mercado e da coerção. Stehr chama este tipo de conhecimento de competências sociais, que são recursos para o indivíduo ter controle sobre a própria vida e que independem da sua ocupação (ibid.).

Como principais competências sociais que esculpem a desigualdade social, Stehr cita as cinco que seguem (STEHR, 2000): $i$. Capacidade de extrair vantagens dos regulamentos legais que regem a conduta social que permitem, por exemplo, o indivíduo obter vantagens no campo de tributos, investimentos e escolaridade; $i$. Facilidade para organizar recursos de proteção - ao patrimônio ou à saúde, por exemplo -, que protege o indivíduo e sua família contra desvalorizações estruturais ou excessivas; iii. Autoridade para falar, originada da competência do indivíduo de 
se expressar, que resulta, por exemplo, na dificuldade de leigos contestarem especialistas e, como consequência, de disputarem "a verdade"; $i v$. Capacidade de se preparar para desafios, que é resumida como o conhecimento dos indivíduos para contestar as práticas dos especialistas e do Estado, além da sua capacidade de burlar os esquemas de vigilância e fiscalização; e v. Capacidade de evitação e exclusão, que é a capacidade de traçar estratégias para evitar situações de risco como a exposição a conflitos, violência e situações de risco à saúde.

\section{DEMOCRACIA E CONHECIMENTO}

A capacidade de agir da sociedade civil está no âmago da democracia e, em consequência, a distribuição do conhecimento na sociedade civil exerce função essencial para o funcionamento dos processos democráticos (STEHR, 2008). Segundo Stehr, "a evolução das sociedades modernas em sociedades do conhecimento conduz à democratização e à negociação das asserções do conhecimento" (ibid., p. 231). No entanto, o crescente volume de informações e a complexidade dos novos conhecimentos científicos causa um alargamento da distância entre o público leigo e aqueles que participam ativamente da produção de conhecimento - os especialistas e cientistas. Essa distância dificulta a reflexão pública quanto às transformações sociais e culturais da sua própria realidade promovidas pelas novas capacidades de agir. A exclusão de parte da população da participação nesses processos e do seu acesso ao conhecimento científico tem consequências graves para a democracia (ibid.).

A popularização do acesso à Internet promoveu a ilusão de que o conhecimento é igualmente produzido, de que é disponibilizado democraticamente e de que todo o conhecimento representa um benefício para a sociedade. Contudo, o desenvolvimento de conhecimento é desigual e depende de várias condições epistemológicas, indicadores sociais, ambições humanas, necessidades e desejos (ADOLF; STEHR, 2017). Nesse contexto, as inovações científicas e tecnológicas são avaliadas conforme as preferências, moral, crenças e visões de mundo do público em geral. As controvérsias da ciência e sua regulamentação - exercida pelas instituições sociais - estimularam a desconfiança e cautela da sociedade diante das novas capacidades de agir. Portanto, a resistência das pessoas leigas quanto às novas informações e conhecimentos não deve ser interpretada como originada da ingenuidade e ignorância das pessoas, mas de sua incerteza e prudência (STEHR, 2008).

Ao contrário de outros bens, como água e alimento, não é possível dar conhecimento, pois aprender é uma atividade individual. Numa sociedade do conhecimento, essa característica propicia a formação de uma aristocracia intangível, uma elite de especialistas dotados do conhecimento científico que associado a outras condições sociais - lhes conferem poder e autoridade. Em relação a questões de políticas públicas e em organizações civis, a ciência perde sua efetividade imediata - devido às limitações e dificuldades de pô-la em prática mencionadas anteriormente - e ganha tons autoritários, reforçados pelo caráter aristocrático dos especialistas (ADOLF; STEHR, 2017).

Segundo Stehr, nas sociedades do conhecimento "as fronteiras entre expertise e saber cotidiano são muito menos delimitadas e muito mais robustas” (STEHR, 
2008, p. 232). São menos delimitadas, pois, com o maior acesso ao conhecimento, os conhecimentos científicos e cotidianos se misturam e se mesclam. Porém, são mais robustas devido à grande complexidade e volume do conhecimento científico, principalmente das ciências naturais, dificultando que o cidadão comum transponha as barreiras para seu acesso e compreensão. Por esses motivos, a percepção da população leiga em relação ao conhecimento científico se aproxima de outras práticas sociais, perdendo sua imagem de conhecimento único e incontestável construída durante o período iluminista (STEHR, 2008). Somado a isso, o crescente descrédito e desconfiança da sociedade civil em relação à ciência, em contraposição à crescente reivindicação da comunidade científica de que as decisões políticas sejam feitas baseadas no conhecimento científico, acentua a tensão entre especialistas e sociedade civil no debate público acerca das novas capacidades de ação. Como efeito, há um aumento na crença de que a população civil deve ter maior participação na ciência, em um diálogo amplo com cientistas e especialistas (ADOLF; STEHR, 2017).

Além do distanciamento da população leiga da ciência, e do papel exercido por especialistas e cientistas, as questões sobre a relação entre conhecimento científico e democracia incluem a contestação da ideia de que conhecimento é uma propriedade (ibid.) - ainda que em uma sociedade do conhecimento. Se por um lado se defende que o conhecimento deve ser tratado como uma propriedade para que a inovação ocorra, dando aos seus autores os devidos direitos, por outro lado se defende que a base da ciência é o próprio conhecimento, de forma que esse não pode ser mantido em segredo (ibid.). Adicionalmente, o fato do estoque geral de saber - o conhecimento distribuído responsável por um considerável aumento da capacidade de ação das pessoas - constituir um bem público, dificulta a defesa de que o conhecimento adicional é necessário, apesar de esse ser o conhecimento que se converte em lucro (STEHR, 2008).

O crescente engajamento político da sociedade civil, sua influência no debate público e nas decisões públicas em temas como mudanças climáticas, aborto, transgênicos etc., evidencia que as sociedades modernas não se encaminharam para uma tecnocracia, como previsto por alguns teóricos (ADOLF; STEHR, 2017). Para Stehr, o principal argumento que desmistifica a tecnocracia é a realidade social em si; é o simples fato de que as atuais sociedades modernas não são tecnocracias (STEHR, 2018).

Atualmente, as decisões cruciais são resolvidas mais segundo os fins competitivos da ação social do que sobre os meios técnicos o que, segundo Stehr, não poderia ser diferente, pois o poder dos especialistas e técnicos é autodestrutivo. Isso ocorre visto que o poder de um especialista está apenas na linha de frente do progresso. Assim que sua área é coberta, assim que suas descobertas e inovações possam ser transformadas em regras, programas ou tecnologias, seu poder desaparece. Por isso, seu poder é frágil e está constantemente se deslocando para o próximo especialista (ADOLF; STEHR, 2017).

\section{PRIMEIRAS REFLEXÕES SOBRE A TEORIA DA SOCIEDADE DO CONHECIMENTO}

Apesar de as origens da TSC estarem associadas à análise de países do norte Global, os autores não discutem sua teoria em casos específicos, 
ignorando os diferentes efeitos da Sociedade do Conhecimento em países com distintas características econômicas e sociais. Numa análise contemporânea das consequências da Era do Conhecimento no Brasil, destacam-se reflexões centradas no papel do acesso e da difusão da informação, do conhecimento e das Tecnologias de Informação e Comunicação no desenvolvimento, na sociedade, na economia e na política do país. Destaca-se também a discussão crítica quanto às consequências da globalização em países periféricos, principalmente quanto à não globalização da geração e difusão de conhecimento e inovação (e.g. ALVES; BAUMGARTEN, 2019; MACIEL; ALBAGLI, 2011). Uma aplicação local e propositiva da TSC em países do Sul Global requer sua articulação com análises contemporâneas e locais, tais como as mencionadas nesse parágrafo.

Ainda assim, a TSC se mostra potente para a análise de fenômenos, incluindo no Brasil, centrados no conhecimento, como, por exemplo, a proliferação de notícias falsas. A era da pós-verdade - em que a desinformação foi potencializada - tem sido assunto de destaque na última década, em especial após as eleições presidenciais dos Estados Unidos da América (EUA) e do Brasil, marcadas pela difusão de notícias falsas (TRÄSEL; LISBOA; VINCIPROVA, 2019). Em consonância, a TSC apresenta a capacidade de negar as instituições - e suas "verdades" - e a diminuição do senso de responsabilidade individual, frutos da possibilidade da não-participação e do não-comprometimento, como características das sociedades modernas. Sem credibilidade, publicações de instituições de jornalismo e de ciências - tradicionalmente acreditadas como comprometidas com a descrição de fatos - passam a ter o mesmo peso que opiniões individuais e conteúdos fabricados. Pode-se pensar que a negação das instituições poderia aumentar a responsabilização individual, já que - ao não seguir ou creditar nenhuma instituição - o indivíduo passaria a ser o responsável por suas decisões. Contudo, o não comprometimento possibilita a exteriorização da responsabilidade. Como exemplo, o fato de a responsabilização pela disseminação de conteúdo falso recair sobre os meios e instituições - plataformas digitais como Facebook e Twitter -, e não sobre os indivíduos, evidencia o explicado acima.

A crise política vivida no Brasil em 2020 pode também ser lida pelas lentes da TSC. A negação das instituições é uma das principais características do presidente da república: um indivíduo que diz não à ciência, à democracia, ao judiciário, à mídia; exerce o direito a dizer não a qualquer oposição (e.g. TOLLEFSON, 2019). A negação pode ser vista também nos recentes levantes antirracistas (e.g. SIMÕES, 2020), que apesar de não serem novos, ganham maior aceitação na negação coletiva de instituições como a polícia, e também de todo sistema judiciário e da mídia - apesar de negarem aspectos distintos dos do Presidente. De maneira similar, os movimentos anticorrupção, surgidos em 2013, negavam a política e qualquer partido, apresentando-se como livres de instituições. Segundo a TSC, esses fatores levam à crise na gestão de problemas comuns e a perda de autoridade das instituições, evidenciados no Brasil pelas dificuldades que os sucessivos ministros da saúde e governadores dos estados têm tido em gerir a crise sanitária promovida pelo surto de COVID-19 (e.g. JUNQUEIRA; MACHIDA, 2020), seja pela dificuldade de conduzir a população em geral a seguir suas orientações, seja nas tensões e divergências internas. 
A leitura da TSC apresentada levanta ainda alguns questionamentos que merecem ser desenvolvidos. Dentre eles, a posição de vantagem de cientistas e engenheiros como detentores do conhecimento científico tecnológico. Apesar desse conhecimento não ter valor de superioridade intrínseco, tem um valor econômico e político superior decorrentes da sua importância nesses campos. A vantagem competitiva que representa, em especial quando é incremental, concede àqueles que o dominam uma posição de vantagem. Não se pode pensar que o poder adquirido com essas vantagens é compulsório e absoluto; depende de outras condições que variam desde individuais até sociais, de maneira que não garantem maior acúmulo de poder político e social do que outros setores da sociedade, nem de capital econômico. Tal afirmação deve ser entendida apenas como um indicativo de que cientistas e engenheiros são os detentores de um bem (conhecimento) de alto valor econômico nas sociedades do conhecimento.

A ciência e a engenharia variam desde as áreas mais abstratas e teóricas, até concretas e práticas; da mesma forma, ambas podem variar desde aplicações mais tradicionais, como a Engenharia Civil, até aplicações mais modernas, como a Engenharia Física. Não há, portanto, uma relação fixa entre ciência e engenharia e conhecimentos escassos, apesar de ser evidente que essas são as formações que mais os envolvem. No Brasil, essa distinção ganha relevância em decorrência do menor desenvolvimento científico e tecnológico, se comparado a país do Norte Global. De tal forma que é preciso maior aprofundamento na pesquisa e discussão para compreender em que medida os conhecimentos dos cientistas e engenheiros no país representam vantagens.

Há também que se considerar como as leis de propriedade intelectual podem limitar o poder e autonomia deles. Corporações e indústrias se utilizam desses mecanismos para dominar os conhecimentos acerca das tecnologias que desenvolvem. Apesar de serem os engenheiros e cientistas aqueles com a capacidade de agir, são as instituições quem têm o poder legal para controlar a ação (associadas às suas propriedades intelectuais). Há então uma tensão entre esses dois elementos que, por um lado, reduzem o poder de ação dos profissionais, e por outro, os mantém em posições de vantagem relativas entre si e em relação a outras profissões. Tal reflexão põe em questão a real vantagem que esses profissionais têm como indivíduos.

Adicionalmente, as peculiares características do conhecimento descritas na seção anterior, como sua intangibilidade, o valor econômico do conhecimento adicional, a escassez artificial dos conhecimentos e a estratificação social baseada nas competências sociais, subsidiam o questionamento quanto à privatização do conhecimento, ampliando as discussões quanto às implicações sociais de se tratar o conhecimento como uma propriedade. Essa visão possibilita que sejam aprofundados os debates sobre a liberdade do conhecimento, lideradas por movimentos como o de Recursos Educacionais Abertos (REA), o da Ciência Aberta e das Tecnologias Livres - movimentos esses que advogam, desde o final do século XX e início do século XXI, pela ampliação do acesso a conteúdos e obras sobre ciência, tecnologia e educação (ALBAGLI; CLINIO; RAYCHTOCK, 2014; PEZZI et al., 2017; SANTANA; ROSSINI; PRETTO, 2012).

$\mathrm{O}$ reconhecimento do protagonismo do conhecimento leva à ponderação da importância dos recursos materiais como recursos produtivos. A TSC não defende, em nenhum momento, que a relevância política e econômica desses 
recursos possa ser desconsiderada, de maneira que se mantém sendo fonte tanto de crescimento econômico como de conflitos. A exemplo, como destacado por um(a) parecerista deste artigo, diversas guerras pelo domínio de matérias-primas, em especial o petróleo, eclodiram nas últimas décadas, evidenciando sua importância econômica e política. ${ }^{8}$ Seria de se esperar, portanto, conflitos pelo controle de "recursos de conhecimento". As peculiaridades do conhecimento - como sua impossibilidade de ser transferido e apropriado "à força”, ou por decreto - faz com que embates armados não sejam meios eficientes de o "saquear", ao contrário dos recursos materiais. Esses fatores exigem a adaptação das estratégias de guerra. Por exemplo, o domínio da região do Vale do Silício (EUA) não significaria um domínio sobre o desenvolvimento de altas tecnologias de eletrônica e informática; já o domínio sobre Cristalina (GO), onde se encontra uma grande mina de silício do Brasil, poderia resultar no domínio sobre a extração desse minério.

Um exemplo de adaptação das estratégias de guerra mencionada, relacionada com uma guerra política e comercial motivada pela escassez do conhecimento, pode ser identificada no recente embate entre China e EUA sobre o domínio da tecnologia 5G (e.g. MUÑOZ; MARS, 2019). O aumento de tarifas de produtos importados da China e a suspensão do suporte da Google a celulares da Huawei é entendido como um ataque dos EUA à China, na tentativa de frear a disseminação da tecnologia, motivada, em especial, pelo receio das vantagens econômicas, bélicas e de espionagem que o domínio chinês do 5G, em conjunção com a Inteligência Artificial (IA), poderiam agregar (e.g. MUÑOZ; MARS, 2019). Tanto a 5G quanto a IA podem ser entendidas, a luz da TSC, como conhecimentos incrementais que representam vantagens em diversas áreas para quem as domina. Guerras por conhecimentos escassos se apresentam também na dimensão jurídica, onde grandes corporações se utilizam das leis de propriedade intelectual para se apropriar de novos processos e ideias e impedir - ou enfraquecer - $\mathrm{O}$ surgimento de concorrentes e garantir vantagens competitivas.

Na busca por críticas às teorias sobre Sociedades do Conhecimento, encontramos o trabalho de Duarte (2013). Contudo, o autor não especifica a quais autores(as) e linhas se refere. Seus comentários abordam aspectos das teorias que não são encontrados na TSC. Por isso, não é possível construir um diálogo completo entre a TSC e suas críticas. Ainda assim, serão brevemente discutidos alguns de seus apontamentos para que melhor se entenda essa discrepância. Ao contrário do que Duarte assume, de que teorias sobre sociedades do conhecimento pressupõem uma democratização do conhecimento, a TSC engloba uma extensa discussão, já sintetizada neste artigo, sobre as influências da não socialização do conhecimento nas desigualdades sociais. Da mesma forma, a análise de que o conhecimento não é a apropriação da realidade pelo pensamento, mas uma convenção social, não se aplica à TSC. Apesar de ser possível afirmar que, para Stehr, o conhecimento científico é uma convenção cultural, isso não significa afirmar que todo conhecimento precisa ser creditado como tal para ter seu valor de ação. Para a teoria, o conhecimento é capacidade de ação, e não depende que as informações e/ou habilidades mobilizadas reflitam alguma realidade particular, nem que sejam validadas. Dessa forma, a teoria de Stehr se distancia das críticas de Duarte.

A ampla aceitação de um "conhecimento" como verdade está sujeita a aspectos culturais, históricos, políticos e econômicos. Logo, há conteúdos que são classificados como "conhecimento" mas que, da perspectiva da TSC, são 
informação. A validade social dada ao conhecimento científico, portanto, não o faz mais ou menos explicativo, nem eficiente; mesmo que uma informação seja tida como verdadeira ela não será um conhecimento se não puder, tendo-se os meios necessários, ser mobilizada como ação. Não se pode ignorar, contudo, que sua aceitação como verdade influenciará na sua aplicabilidade, dado que sua mobilização enfrentará menos barreiras sociais e culturais.

Importante destacar que ter capacidade de ação não significa ser prático. Ação, nesse contexto, inclui a dimensão concreta e teórica. Disso resulta que não é central na teoria a preocupação em relacionar o conhecimento com a realidade, pois seu valor está na capacidade de ação. Tal relação está mais associada aos resultados do que às origens: não importa como o conhecimento foi produzido, importa se ele capacita a agir. Assim, mesmo que alguns conhecimentos não sejam resultado de uma apropriação da realidade pelo pensamento, são capazes de criá-la e transformá-la (ADOLF; STEHR, 2017).

Por exemplo, uma notícia falsa sobre a eficácia de um remédio em curar uma doença, mesmo que seja instituída como verdade, não capacita ninguém a curar a doença. Porém, a mesma notícia pode capacitar ações no campo político e midiático, sendo, portanto, conhecimento. Ao afirmar que a aplicação do conhecimento não é óbvia nem direta, entende-se que Stehr indica que a ação não necessariamente está diretamente associada ao conteúdo que o compõe. De maneira similar, o que faz da mitologia de um povo conhecimento não é a descrição da realidade, mas as capacidades de ação que representam, da agricultura até a política.

\section{EDUCAC̣ÃO CTS NA SOCIEDADE DO CONHECIMENTO}

A produção de Stehr, compreendida como parte da Sociologia do Conhecimento (ADOLF; STEHR, 2017), pode ser entendida dentro dos estudos de CTS como o que Strieder (2012) chamou de "ciência do ponto de vista da produção social". Essa linha favorece a investigação desde os aspectos sociais, econômicos, religiosos e culturais do conhecimento científico, aos aspectos conceituais. Compõem também essa linha autores como Durkhein, Merton, Mannhein e Bourdieu (STRIEDER, 2012), todos igualmente referências base da TSC (STEHR, 2018). Stehr dialoga com esses autores atualizando e aprofundando a discussão tendo o conhecimento como variável central, analisando a relação do conhecimento científico e tecnológico com a sociedade, mas também com outras formas de conhecimento.

$\mathrm{Na}$ Educação CTS, a TSC pode contribuir com o aprofundamento de discussões já em andamento sobre a educação científica em sociedades com economia baseada no conhecimento. A exemplo, na Abordagem CTS Norte-Americana, Aikenhead et al. (2011) reexaminam a função, objetivos e práticas da alfabetização científica em países economicamente desenvolvidos, chamados de "Sociedades do Conhecimento". A base na qual se apoiam (GILBERT, 2007 apud AIKENHEAD; ORPWOOD; FENSHAM, 2011), contudo, aponta para uma concepção reduzida de sociedades do conhecimento. Apesar de explicitar a associação do conhecimento à ação, o reduz ao científico e tecnológico, ignorando a relevância, e a capacidade de ação, de outras formas de conhecimento nas tomadas de decisões políticas e sociais e na resolução de problemas cotidianos e profissionais. Também não explicita 
outros aspectos dessas sociedades, como as estruturas das desigualdades sociais e as relações entre indivíduos e instituições. Ao se considerar o valor econômico e democrático do conhecimento científico sem, com isso, ignorar que outras formas de conhecimento também são dinâmicas e influenciam nas desigualdades sociais, a TSC se apresenta como uma atualização das perspectivas primeiramente adotadas, aprofundando a análise da função social da ciência e da educação científica.

Quanto às sociedades do conhecimento, Núñez (2000) se contrapõe à interpretação de que o conhecimento se sobrepõe às condições e circunstâncias sociais, eliminando desigualdades. Similarmente, a visão apresentada na TSC busca discutir as crescentes influências dos conhecimentos - não só o científicotecnológico - nas desigualdades sociais, sem propor que sua “distribuição" levaria à igualdade de oportunidades. Pelo contrário, os autores discutem a impossibilidade de se "distribuir" conhecimento, como é feito com outros bens, e apresentam as competências sociais como capacidades de se proteger e evitar danos (à saúde, econômicos, aos bens materiais etc.) aos quais estão vulneráveis.

A Alfabetização Científico-Tecnológica, como discutida por Auler e Delizoicov (2001), deve buscar fomentar a formação de um sujeito emancipado e com uma leitura crítica do mundo. Para isso, é essencial que o ensino técnicocientífico seja contextualizado e problematizador, buscando uma compreensão das relações CTS. Da perspectiva da TSC, é possível também se questionar sobre quais as capacidades de ação se associam, e complementam, as experiências e saberes dos estudantes com objetivo de ampliar as habilidades cognitivas para interpretação da informação, mas também para propiciar a criação de conhecimento adicional. Em uma tentativa de associar os saberes locais com conhecimentos científicotecnológicos, o conhecimento adicional produzido pode estar à serviço dos seus próprios produtores, considerando problemas e necessidades locais, bem como características do seu contexto de criação. Assim, pode-se pensar numa Alfabetização Científico-Tecnológica que não só emancipa o pensamento do sujeito, ao promover uma visão crítica do mundo, mas também o emancipa para a criação e modificação do mundo, tal como a educação hacker (PRET'TO, 2017).

Similarmente, a Alfabetização Científico-Tecnológica, como componente de um currículo de CTS, tem como objetivo "construir conhecimentos, habilidades e valores necessários para [o estudante] tomar decisões responsáveis sobre questões de ciência e tecnologia na sociedade e atuar na solução de tais questões" (SANTOS; MORTIMER, 2000). Sobre a perspectiva teórica proposta, pode-se dar um novo olhar sobre esses currículos. Seus conteúdos e discussões, enquanto capacidades de ação que se pretende ensinar, podem passar a considerar não só as relações CTS diretamente, mas também considerar as novas relações entre as instituições e indivíduos, a compreensão de que a capacidade de ação necessita de poder para se efetivar ação, bem como as características práticas, mas limitadas, do conhecimento científico, e o papel do conhecimento na estratificação social e no fortalecimento das democracias. Para completar seu objetivo de fomentar a formação de cidadãos capazes de compreender e atuar na solução de problemas sociais, é preciso promover uma compreensão mais ampla do funcionamento e estrutura das sociedades contemporâneas. Ainda assim, a introdução de conteúdos aos currículos não resulta, necessariamente, em uma discussão adequada sobre os assuntos (SANTOS; MORTIMER, 2000). Se faz necessário 
aprimorar as metodologias de transposição didática a fim de que as capacidades de ação almejadas não sejam distorcidas ou perdidas.

A relação entre conhecimento e desigualdades sociais em si não é inovadora, porém a especificação dos tipos de competências sociais que estratificam os indivíduos define mais explicitamente os tipos de capacidades de ação necessárias para a superação de situações de vulnerabilidade social e econômica, e também para possibilitar a autonomia e emancipação do indivíduo das estruturas de dominação, como propõem Freire (1996). Assim, pesquisas e debates quanto aos caminhos que a escola deve seguir para promover a redução das desigualdades sociais e desenvolvimento da autonomia, em especial o CTS brasileiro, podem se apoiar nessa teoria para identificar quais conteúdos e práticas ampliam as competências sociais dos indivíduos, em direção a uma educação científica crítica (SANTOS; MORTIMER, 2000).

A teoria também acrescenta ponderações importantes quanto à influência da ciência e da tecnologia na governança das sociedades atuais. Auler e Delizoicov (2001) previam, há quase 20 anos, que um ensino de ciências que não questionasse os mitos sobre a ciência e tecnologia conduziria a sociedade a uma tecnocracia. Porém, como argumenta Stehr, as sociedades do conhecimento não são tecnocracias (STEHR, 2018). Essa divergência levanta uma série de questionamentos a serem investigados, como, por exemplo: i. os mitos salvacionistas e da neutralidade da ciência ainda predominam no senso comum? ii. o ensino de ciências, por si só, é, ou foi, capaz de perpetuar, ou de modificar, esses mitos? iii. se a ciência é deslegitimada por figuras públicas, por senadores e até presidentes (e.g. GORTÁZAR, 2019), como pode tecnologias modernas serem acriticamente e massivamente adotadas por escolas e governos (PARRA et al., 2018)? Seria esse um estágio intermediário à tecnocracia, ou uma derivação dela?

É importante destacar que a TSC está alinhada com visões mais consensuais, no CTS, sobre o conhecimento científico e tecnológico, tais como a compreensão de que o desenvolvimento científico e tecnológico é um processo social, não é neutro, nem é sempre positivo, e seu desenvolvimento não conduz obrigatoriamente ao bem-estar social (NÚÑEZ JOVER, 2000), mas sua apropriação pela população fortalece a democracia (ACEVEDO DÍAZ; ALONSO; MAS, 2003). Sua percepção sobre tecnologia se alinha a autores como Feenberg, numa visão que incorpora pressupostos instrumentalistas e substancialistas (STRIEDER, 2012). Assim, a TSC inicialmente se mostra como compatível com pensamentos da Abordagem CTS, podendo então ser incorporada aos estudos da área na compreensão das relações entre os conhecimentos, em especial o científico e tecnológico, e a sociedade. A importância econômica e social do conhecimento é inegável tanto na TSC quanto no CTS, contudo a forma como se relaciona com outras formas de poder e com as desigualdades sociais é ainda um ponto de atrito que merece ser esclarecido.

No Brasil, alguns pontos em especial chamam atenção. A extensão com que se pode afirmar que os direitos à cidadania e bem-estar social são garantidos, em especial para populações periféricas, pretos e indígenas, pode alterar o peso do conhecimento nas estruturas das desigualdades sociais. De maneira similar, o baixo desenvolvimento científico e tecnológico do país põe em questão a posição de privilégio que cientistas e engenheiros ocupam na sociedade, dado que os conhecimentos que mobilizam não são, como em países mais desenvolvidos tecnologicamente, majoritariamente incrementais. É preciso melhor compreender como essas e outras especificidades da 
realidade brasileira interagem com a TSC, para que melhor se possa entender como a importância econômica e social do conhecimento afetam essa sociedade em especial.

\section{CONSIDERACְÕES FINAIS}

A TSC de Stehr descreve o conhecimento a partir de um viés sociológico, omitindo os aspectos cognitivos e psicológicos dele. Ela traz um retrato das sociedades modernas enfatizando aspectos econômicos do conhecimento e sua relação com outros construtos como privatização e desigualdade social. Apesar de não ser uma teoria que tem como finalidade a discussão das relações CTS, realiza isso ao ter como tema central de discussão a relação entre o conhecimento e a sociedade. Partindo de uma concepção de que o conhecimento não é neutro, e nem reflete uma única verdade, evidencia que tampouco o conhecimento científico o é. Similarmente, apesar do autor não destacar em seus trabalhos a posição das escolas, nem do ensino de maneira geral na sociedade, diversos aspectos de sua teoria podem ser explorados a partir da ótica da pesquisa em ensino de ciências.

Apesar de Stehr discutir o pensamento acerca da ciência de autores como Merton, Durkheim e de Mannheim, não posiciona a TSC em nenhuma linha epistemológica em específico. $\mathrm{O}$ autor destaca que a produção do conhecimento científico está sujeita a influências sociais e também que pode influenciar, e ser influenciada, por conhecimentos convencionais e cotidianos, o senso comum, numa relação dinâmica de crescimento. Contudo, o que é de fato ciência, e como ocorre sua produção, é pouco discutido; maior atenção é dada para a desconstrução da concepção positivista e de superioridade do conhecimento científico.

Com a finalidade de aproximar a TSC da Educação CTS, o artigo realizou algumas discussões com o potencial de resultarem em novas, ou atualizadas, reflexões sobre o ensino de ciências e quanto à produção de conhecimento científico-tecnológico. Destaca-se principalmente reflexões quanto a alfabetização científico-tecnológica (AULER; DELIZOICOV, 2001; SANTOS; MORTIMER, 2000), incluindo nas Sociedades do Conhecimento (AIKENHEAD; ORPWOOD; FENSHAM, 2011), levando em consideração reflexões críticas quanto a elas (DUARTE, 2013; NÚÑEZ JOVER, 2000).

Destacou-se ainda a importância de uma releitura da teoria considerando especificidades do contexto social e político atual dos países da América Latina e do Caribe, bem como especificidades da realidade brasileira, para subsequentes pesquisas e proposições de ações concretas, objetivas e não ingênuas. É igualmente fundamental considerar ponderações quanto à garantia de direitos básicos e quanto à posição social de cientistas e engenheiros. Dentre as limitações da teoria, ressaltase ainda a ausência da associação direta entre a estratificação do indivíduo e suas identidades sociais, culturais e biológicas. O estudo dessas interseccionalidades é essencial para que pesquisas baseadas nesse referencial teórico não reproduzam, de forma não intencional, as estruturas de opressão dominantes.

Em síntese, a TSC, na acepção de Nico Stehr, se apresenta como um referencial teórico contemporâneo, amplo e estruturado que fornece recursos teóricos para a ampliação das pesquisas em ensino. Sua contribuição no ensino de ciências tende a aprofundar as discussões quanto à função social do conhecimento científico, aprimorando, assim, a compreensão das relações CTS. 


\section{AGRADECIMENTO}

Ives Araujo agradece ao CNPq pela bolsa produtividade em Pesquisa.

\section{REFERÊNCIAS}

ACEVEDO DÍAZ, J. A;; ALONSO, Á; V.; MAS, M. Papel de la educación CTS en una alfabetización científica y tecnológica para todas las personas. Revista Electrónica de Enseñanza de las Ciencias, v. 2, p. 80-111, 2003.

ADOLF, M. T.; STEHR, N. Knowledge: is knowledge power? $2^{\circ}$ ed. London; New York: Routledge, Taylor \& Francis Group, 2017.

AIKENHEAD, G.; ORPWOOD, G.; FENSHAM, P. Scientific Literacy for a Knowledge Society. Exploring the Landscape of Scientific Literacy. New York: Taylor and Francis Group, 2011. p. 28.

ALBAGLI, S.; CLINIO, A.; RAYCHTOCK, S. Ciência Aberta: correntes interpretativas e tipos de ação. Liinc em Revista, Desafios contemporâneos à produção colaborativa em ciência, tecnologia e inovação. v. 10, p. 17, 2014.

ALVES, D.; BAUMGARTEN, M. (Org.). Conhecimentos e sociedade: teorias, políticas e controvérsias. Brasília, DF: Verbena Editora, 2019.

AULER, D. Novos Caminhos para a Educação CTS: ampliando a participação. In: IV SIMPÓSIO NACIONAIS DE TECNOLOGIA E SOCIEDADE, 2011. Anais [...]. Curitiba: Programa de PósGraduação em Tecnologia (UTFPR), associação Brasileira de Estudos Sociais das Ciências e das Tecnologias (ESOCITE.BR), p. 10. 2011.

AULER, D.; DELIZOICOV, D. Alfabetização científico-tecnológica para quê? Ensaio Pesquisa em Educação em Ciências (Belo Horizonte), v. 3, n. 2, p. 122-134, 2001. DOI 10.1590.

BATISTA DE FREITAS, D. Modos de discurso usados por licenciandos em Física da UFRGS em questões sociocientíficas. 2019. Dissertação de Mestrado em Ensino de Física - Universidade Federal do Rio Grande do Sul, Porto Alegre, Brasil, 2019.

DAGNINO, R. Mais além da participação pública na ciência: buscando uma reorientação dos Estudos sobre Ciência, Tecnologia e Sociedade em Ibero-américa. Revista Iberoamericana de Ciencia, Tecnología, Sociedad e Inovación, v. 7, dez. 2006.

DUARTE, N. Sociedade do conhecimento ou sociedade das ilusões? Quatro ensaios críticodialéticos em filosofia da educação. 1ª ed. Campinas, SP: Autores Associados, 2013. v. 13. (Coleção Polêmicas do Nosso Tempo).

FREIRE, P. Pedagogia da Autonomia. Brasil: Paz e Terra, 1996.

GORTÁZAR, N. G. O que há por trás das chamas na Amazônia. 4 nov. 2019. EL PAÍs. Brasil. Disponível em: https://brasil.elpais.com/brasil/2019/10/22/eps/1571696000_250069.html. Acesso em: 4 dez. 2019.

JUNQUEIRA, C.; MACHIDA, K.. Após 29 dias no cargo, Nelson Teich pede demissão do Ministério da Saúde. 15 maio 2020. CNN Brasil. Disponível em: https://www.cnnbrasil.com.br/ politica/2020/05/15/nelson-teich-pede-demissao-do-ministerio-da-saude. Acesso em: 18 jun. 2020. 
MACIEL, M. L.; ALBAGLI, S. (Org.). Informação, conhecimento e poder: mudança tecnológica e inovação social. Rio de Janeiro, RJ: Garamond, 2011.

MUÑOZ, Ramón; MARS, Amanda. O problema não é seu celular Huawei, o problema se chama 5G. 27 maio 2019. EL PAÍS. Disponível em: https://brasil.elpais.com/brasil/2019/05/25/ economia/1558795538_036562.html. Acesso em: 18 jun. 2020.

NÚÑEZ JOVER, J. La ciencia y la tecnología como procesos sociales. Lo que la educación científica no debería olvidar. 2000. Sala de Lectura CTS+I - Organización de Estados Iberoamericanos. Disponível em: https://www.oei.es/historico/salactsi/nunez00.htm\#a. Acesso em: 18 jun. 2020.

PARRA, H. et al. Infraestruturas, economia e política informacional: o caso do google suite for education. Mediações - Revista de Ciências Sociais, v. 23, n. 1, p. 63, 6 jul. 2018.

PEZZI, R. P. et al. Desenvolvimento de tecnologia para ciência e educação fundamentado nos preceitos de liberdade do conhecimento: o caso do Centro de Tecnologia Acadêmica. Liinc em Revista, v. 13, n. 1, p. 205-222, maio 2017.

PRETTO, N. De L. Educações, Culturas e Hackers: escritos e reflexões. Salvador: EDUFBA, 2017.

RUSER, A. Nico Stehr, Sociology, Knowledge and the Sociology of Knowledge: An Introduction. In: ADOLF, M. T. (org.). Nico Stehr: pioneer in the theory of society and knowledge. Pioneers in Arts, Humanities, Science, Engineering, Practice. Germany: Springer, 2018. v. 16.

SANTANA, B.; ROSSINI, C.; PRETTO, N. De L. (Org.). Recursos Educacionais Abertos: práticas colaborativas e políticas públicas. $1^{a}$ ed. Salvador: Edufba; São Paulo: Casa da Cultura Digital, 2012.

SANTOS, W. L. P. dos; MORTIMER, E. F. Uma análise de pressupostos teóricos da abordagem C-T-S (Ciência - Tecnologia - Sociedade) no contexto da educação brasileira. Ensaio Pesquisa em Educação em Ciências (Belo Horizonte), v. 2, n. 2, p. 110-132, dez. 2000. DOI 10.1590/1983-21172000020202.

SIMÕES, N. Manifestantes convocam novos protestos por vidas negras em São Paulo e no Rio de Janeiro. 5 jun. 2020. Alma Preta. Disponível em: https://almapreta.com/editorias/ realidade/manifestantes-convocam-novos-protestos-por-vidas-negras-em-sao-paulo-e-no-rio-dejaneiro. Acesso em: 18 jun. 2020.

STEHR, N. Da desigualdade de classe à desigualdade de conhecimento. Revista Brasileira de Ciências Sociais, v. 15, n. 42, p. 101-112, fev. 2000.

STEHR, N. Liberdade é filha do conhecimento? Tempo Social, v. 20, n. 2, p. 221-234, nov. 2008. DOI 10.1590/S0103-20702008000200011.

STEHR, N. Nico Stehr: pioneer in the theory of society and knowledge. Switzerland: Springer Nature, 2018.

STRIEDER, R. B. Abordagens CTS na educação científica no Brasil: sentidos e perspectivas. 2012. Tese de Doutorado em Ensino de Física - USP, São Paulo, 2012. DOI 10.11606/T.81.2012. tde-13062012-112417.

STRIEDER, R. B.; KAWAMURA, M. R. D. Educação CTS: Parâmetros e Propósitos Brasileiros. Alexandria: Revista de Educação em Ciência e Tecnologia, v. 10, n. 1, p. 27-56, maio 2017.

TOLLEFSON, J. ‘Tropical Trump’ sparks unprecedented crisis for Brazilian science. Nature, v. 572, n. 7768, p. 161-162, 1 ago. 2019. https://doi.org/10.1038/d41586-019-02353-6. 
TRÄSEL, M.; LISBOA, S.; VINCIPROVA, G. R. Pós-verdade e confiança no jornalismo. Brazilian Journalism Research, v. 15, n. 3, p. 452-473, 30 dez. 2019. https://doi.org/10.25200/BJR. v15n3.2019.1211.

\section{NOTAS}

1 Uma tecnocracia é uma sociedade na qual as instituições sociais seriam governadas por técnicos, especialistas, em vez de autoridades e administradores(as). Nelas, as burocracias seriam conduzidas por um padrão exclusivo de eficiência, sem nenhuma influência da sociedade civil (STEHR, 2018).

2 Os autores não aprofundam suas discussões nos aspectos cognitivos do conhecimento, de forma que os atributos psicológicos e sociais do conhecimento não são articulados. Ainda assim, é possível identificar que se baseiam em autores como John Dewey e Kathleen Carley (ibid., p. 29).

3 Ainda assim, o poder não é dependente do conhecimento. Outras formas de poder, como força física, econômica, militar, de meios de produção, cultural e religiosa, permanecem sendo formas de autoridade e poder (ibid.).

4 Os autores dialogam com a teoria de Foucault, defendendo que ele alegava que poder e conhecimento não eram uma mesma entidade, e sim complementares. Sugerem, inclusive, que Foucault foi, além de filósofo, um "proponente da sociologia do conhecimento" (ibid., p. 63).

5 Nesse sentido, custo nominal representa o custo de um serviço ou bem sem ajustes de inflações, taxas, ou custo relacionados. O valor real, por outro lado, considera esses fatores. Por exemplo, o custo para se obter as plantas arquitetônicas de um edifício é muito inferior ao custo para que elas sejam interpretadas, pois esses incluem os custos dos profissionais técnicos capazes de interpretá-lo, dos softwares adequados para sua leitura, dos direitos autorais para seu uso, etc.

6 A não-rivalidade é uma característica de um bem econômico que indica que o seu uso, ou consumo, por uma pessoa não reduz a quantidade disponível para outras .

7 Há também de se considerar outras esferas que possam impedir, direta ou indiretamente, a ação, como as esferas jurídicas, políticas, militares, religiosas e culturais.

8 Uma breve descrição dos conflitos armados motivados pela disputa por petróleo pode ser encontrada na reportagem da BBC News, disponível em: https://www.bbc.com/portuguese/ noticias/2015/12/151203_conflitos_mundiais_petroleo_lgb_gch .

Submetido em 05/02/2020

Aprovado em 31/07/2020

\section{Contato:}

UFRGS - Campus do Vale

Av. Bento Gonçalves, $n^{0} 9500$

Caixa Postal 15051

CEP 91.501-970 - Porto Alegre, RS - Brasil 